
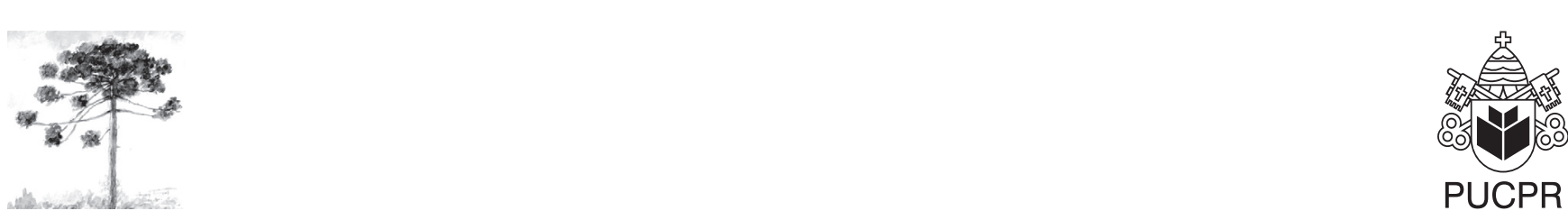

PUCPR

\title{
Análise dos resultados de exames preventivos e de rastreamento de câncer de colo do útero realizados em uma clínica ginecológica particular no município de Curitiba, PR
}

\author{
Analysis of the results of preventives examinations and cervical \\ cancer screening in a gynecological clinic in Curitiba, PR
}

[a] Especialização em Citologia Cérvico-Vaginal pela SBAC, Pontifícia Universidade Católica do Paraná (PUCPR), Curitiba, PR - Brasil.

[b] Especialização em Citologia Cérvico-Vaginal e Líquidos Corporais, Universidade Federal de Santa Catarina (UFSC), Florianópolis, SC - Brasil, e-mail: ni_machado@hotmail.com

[c] Mestranda do Programa de Pós-Graduação em Farmácia da Universidade Federal de Santa Catarina (UFSC), Florianópolis, SC - Brasil.

[d] Especialização em Citologia Cérvico-Vaginal e Líquidos Corporais, Universidade Federal de Santa Catarina (UFSC), Florianópolis, SC - Brasil.

[e] Doutorado em Ciência dos Alimentos pela Universidade Federal de Santa Catarina (UFSC), professor adjunto I da Universidade Federal de Santa Catarina (UFSC), SC - Brasil, e-mail: haas@ccs.ufsc.br

\section{Resumo}

O câncer de colo de útero é o terceiro tipo de câncer mais frequente entre as mulheres brasileiras. Entretanto, a evolução desse câncer é geralmente lenta, permitindo um grande potencial de cura pela prevenção que é realizada pelo teste de Papanicolaou. Esse teste tem como objetivo a verificação de alterações celulares tanto na porção endocervical quanto na ectocervical. No entanto, ele também é útil na detecção ou sugestão da presença de alguns agentes patogênicos como Candida sp, Trichomonas vaginalis, entre outros. Este trabalho tem como objetivo analisar os resultados dos exames preventivos de câncer de colo de útero realizados em uma clínica ginecológica de atendimento particular e conveniado no município de Curitiba, PR. A população de estudo abrangeu 5.964 mulheres com idade entre 14 anos e 84 anos de idade. Os agentes patológicos mais frequentemente encontrados foram a Gardnerella seguida da Candida sp e a maioria dos resultados apresentou resultado negativo para lesão intraepitelial e malignidade (NILM) (95,1\%). Entre as amostras que apresentavam algum tipo de lesão, $100(1,61 \%)$ 
obtiveram diagnóstico citológico de lesão intraepitelial escamosa de baixo grau (LSIL); e 4 para (0,07\%) lesão intraepitelial escamosa de alto grau (HSIL). Atipias em células glandulares foram verificadas em 19 amostras $(0,35 \%)$ e somente 1 adenocarcinoma $(0,02 \%)$ foi relatado na população de estudo. Os resultados apresentados permitem verificar a importância da prevenção desse câncer pelo exame Papanicolaou, já que a detecção precoce de lesões permite que seja adotada uma conduta terapêtica adequada para evitar a progressão da doença.

Palavras-chave: Exame de Papanicolaou. Citologia. Câncer de colo uterino. Agentes patogênicos.

\begin{abstract}
The cervical cancer is the third most common type of cancer in brazilians women. However, the evolution of this cancer is frequently slow, wich allows a high potencial of cure with the prevention, carried out for Papanicolaou examination. This exam has the objective to verify celular alterations in endocervix and ectocervix. However, it is also useful in the detection or suggestion of the presence of patogencis agents like Candida sp and Trichomonas vaginalis. This study has the objective to analyse the results of the preventive examinations of cervical cancer carried out in a gynecological clinic of particular and accorded service in Curitiba, PR. The population of the study included 5.964 women with age between 14 years and 84 years of age. The pathological agents more frequently considered were Gardnerella followed by Candida sp and most of the results presented negative result for injury intra-epitelial and malignance (NILM) (95,1\%). Between the samples that were presenting some type of injury, 100 samples (1,61\%) obtained cytologic diagnosis of low-grade squamous intraepithelial lesions (LSIL) and 4 samples (0,07\%) high-grade squamous intraepithelial lesions (HSIL). Atypical glandular cells was checked in 19 samples (0,35\%) and only 1 adenocarcinoma (0,02\%) was reported in the population of study. The presented results is important to show the importance of the prevention of this cancer with the Papanicolaou test, since the precocious detection of injuries allows the adoption of an appropriate therapeutic conduct that avoids the progression of the disease.
\end{abstract}

Keywords: Papanicolaou examination. Cytology. Cervical cancer. Pathogenical agents.

\section{Introduçáo}

O câncer de colo uterino é uma doença crônico-degenerativa muito temida, em virtude do seu alto grau de letalidade e morbidade. Surgem anualmente mais de 500 mil casos de câncer de colo uterino no mundo, sendo responsáveis por, aproximadamente, 230 mil mortes. No Brasil, é o terceiro mais comum câncer entre as mulheres brasileiras, sendo, para 2008, estimados aproximadamente 19.000 novos casos desse tipo de câncer. $\mathrm{O}$ câncer de colo uterino é o quarto mais frequente na região Sudeste, o segundo nas regiões Sul, Centro-Oeste e Nordeste e, na região Norte, é o mais incidente, descartando os tumores de pele não melanoma $(1,2)$. A taxa de mortalidade do câncer de colo uterino, estimada para o ano de 2006, foi de 5,32/100 mil habitantes do sexo feminino, caracterizando o câncer de colo uterino como um problema de saúde pública $(2,3)$.
A incidência desse tipo de câncer ocorre na faixa etária de 20 a 29 anos e o risco aumenta à medida que se atinge a faixa etária de 45 a 49 anos (1). Graças à extensão do território brasileiro, às diferentes características de suas regiões e à diversidade cultural de sua população, a incidência e a mortalidade do câncer de colo de útero apresentam diferenças de magnitude, sendo importante conhecer o padrão de prevalência e as variações em cada região ao longo do tempo para tentar diminuir a incidência desse câncer (4). A evolução desse câncer, na maioria dos casos, ocorre lentamente, passando por fases pré-clínicas detectáveis e curáveis, sendo, dentre todos os tipos de câncer, o que apresenta um grande potencial de cura pela prevenção (5).

$\mathrm{Na}$ maioria dos casos, esse tipo de câncer está associado a fatores extrínsecos, ou seja, relacionados ao ambiente e aos hábitos de vida, como, por exemplo, a conduta sexual (precocidade do início da 
Análise dos resultados de exames preventivos e de rastreamento de câncer de colo do útero realizados em uma clínica ginecológica particular no município de Curitiba, PR

atividade sexual e promiscuidade), o hábito de fumar e a fatores nutricionais (deficiência de vitamina A) (6). A relação entre câncer do colo uterino e os hábitos sexuais levou à identificação do papilomavírus humano (HPV), reconhecido como fator etiológico para lesões neoplásicas cervicais precursoras e/ou invasoras $(7,8)$.

Os vírus do papiloma humano são vírus não envelopados, de simetria icosaédrica com 72 capsômetos e um genoma de DNA de fita dupla circular. Pertencentes à família Papillomaviridae, os $\mathrm{HPV}$ infectam tanto as mucosas quanto os tecidos cutâneos, podendo ser classificados, segundo seu tropismo, como cutaneotrópicos e mucosotrópicos $(9,10)$. Estudos epidemiológicos têm mostrado que apenas uma pequena fração das mulheres infectadas por tipos oncogênicos de HPV irá progredir para lesão intraepitelial de alto risco e câncer do colo do útero, demonstrando que o HPV é necessário para o desenvolvimento dessa neoplasia, porém, não é condição única, portanto, outros fatores devem ser associados para que ocorra a evolução dessa malignidade (11).

Desde 1988, a principal estratégia utilizada no Brasil para detecção precoce e rastreamento do câncer de colo uterino é a realização de coleta de material para exame citopatológico cérvico-vaginal e microflora, conhecido como exame de Papanicolaou ou citologia oncótica. O exame citopatológico deve ser realizado em mulheres de 25 a 60 anos de idade, uma vez por ano e, após dois exames anuais consecutivos negativos, a cada três anos (12). O exame de Papanicolaou é aceito internacionalmente como o instrumento mais adequado e de baixo custo conhecido e aceito para o rastreamento desse tipo de câncer em mulheres sexualmente ativas $(13,14)$. O teste de Papanicolaou identifica lesões pré-cancerosas que, se tratadas, diminuem a incidência de carcinoma invasor e, consequentemente, a mortalidade pelo câncer de colo uterino.

Com o progresso substancial no conhecimento da resposta do hospedeiro à infecção pelo HPV, vacinas para dez tipos de HPV foram desenvolvidas e, futuramente, poderão ser utilizadas como vacina polivalente. As vacinas utilizadas atualmente têm como alvo os tipos 16 e 18, causadores da maioria dos carcinomas cervicais, e/ou 6 e 11, causadores da maioria dos condilomas (15).

O objetivo deste trabalho foi realizar a análise dos resultados de exames preventivos e de rastreamento de câncer de colo do útero realizados em uma clínica ginecológica particular do município de Curitiba, Paraná.

\section{Metodologia}

Foi realizada uma análise dos resultados dos exames preventivos de colo uterino por meio do método convencional, referente a 5.964 mulheres atendidas no Laboratório de Análises Clínicas São Paulo Ltda, no período de dezembro de 2004 a abril de 2009. Essas pacientes realizaram esse exame por convênios médicos, sindicatos ou atendimento particular.

Para a realização da coleta, introduziu-se um espéculo vaginal e foi realizada a descamação ou esfoliação da superfície do colo e da vagina com auxílio de uma espátula de madeira (espátula de Ayre) e de escova endocervical, abrangendo sempre a região da junção escamocolunar. O esfregaço foi confeccionado em lâmina de vidro e fixado com etanol $96^{\circ}$ ou polietilenoglicol e posteriormente foi realizada a coloração de Papanicolaou (3).

Os resultados avaliados continham o cadastro da paciente com nome e idade, data da coleta e os resultados da realização do exame propriamente dito, que incluíam a classificação do predomínio celular da ectocérvice (atrófico, hipotrófico ou eutrófico), a presença ou não de células endocervicais, componentes inflamatórios (ausente, discreto, moderado, aumentado), citólise, agentes patogênicos e/ou alterações celulares de acordo com a classificação pelo Sistema Bethesda.

\section{Resultados e discussão}

A população de estudo abrangeu 5.964 mulheres com idade entre 14 e 84 anos de idade, com média de 35,5 anos. Do total de coletas realizadas, $4.955(83 \%)$ amostras apresentavam células endocervicais, o que permite classificar a amostra como satisfatória de acordo com o Sistema Bethesda (16), pois atesta que a amostra contém células da junção escamo-colunar, local onde ocorre a grande maioria das alterações celulares $(17,18)$. A porcentagem de falsos negativos na citologia cervical varia de 1,5\% a $55 \%$. Essa variação pode ocorrer graças a diferenças na coleta quanto à obtenção de células endocervicais que determinam a adequação da amostra (19). Outras 
características que podem interferir na adequação da amostra são a falta de identificação correta e/ou de informações clínicas relevantes, presença de sangue, áreas espessas e artefatos de fixação (20).

$\mathrm{Na}$ avaliação do predomínio celular da ectocérvice pode-se classificar 215 (3,6\%) amostras como epitélio atrófico, 5.349 (89,7\%) como epitélio eutrófico e $400(6,7 \%)$ como epitélio hipotrófico. A presença de epitélio atrófico, principalmente em mulheres acima de 60 anos de idade, pode ser justificada pelo hipoestrogenismo que ocorre em mulheres na menopausa (21).

As células intermediárias são ricas em glicogênio e predominam em algumas fases do ciclo sexual mensal feminino. Esse glicogênio é consumido pelos lactobacilos presentes na flora normal, produzindo ácido lático e acidificando o meio como uma forma de proteção contra micro-organismos patogênicos. $\mathrm{Na}$ presença de grande quantidade de células intermediárias e elevado número de lactobacilos, esse consumo do glicogênio torna-se mais exacerbado, podendo ser verificada a presença de citólise, a qual é detectada pela presença de núcleos desnudos com restos celulares espalhados pelo esfregaço (12). A presença de citólise foi verificada em 325 (5,4\%) amostras analisadas.

Os componentes inflamatórios, geralmente representados por exsudação leucocitária, em geral de tipo polimorfonucleares neutrofílicos, estavam ausentes em $192(3,2 \%)$ amostras analisadas, diminuídos em 3.255 (54,6\%), moderados em 1.599 (26,8\%) e intensos em 918 (15,4\%) amostras das mulheres estudadas. Em processo inflamatório intenso, a qualidade da amostra é prejudicada, devendo ser realizado o tratamento e feita nova coleta citológica após três meses (22). Deve-se considerar tal componente em maior ou menor grau praticamente como funcional, uma vez que o colo e a vagina são expostos ao meio ambiente e sofrem ação de pequenos traumatismos durante o coito, duchas, uso de tampões, entre outros. Os processos inflamatórios geralmente são acompanhados por processos infecciosos determinados por agentes microbiológicos, sendo mais comuns a vaginose bacteriana e os desencadeados por Candida sp e Trichomonas vaginalis (23).

A flora vaginal normalé formada predominantemente por lactobacilos e pequena concentração de outras bactérias aeróbicas e anaeróbicas, sendo esse achado normal e não caracterizam infecções que necessitem de tratamento. O desequilíbrio dessa flora resulta em vaginites e/ ou vaginoses (20).
A vaginose bacteriana é considerada, atualmente, a infecção vaginal de maior prevalência em mulheres em idade reprodutiva, sendo definida como uma alteração da microbiota vaginal normal caracterizada pela substituição de lactobacilos, normalmente predominantes, por uma flora composta predominantemente por bactérias anaeróbias estritas e facultativas (Gardnerella vaginalis, Prevotellasp, Bacteroides sp, Mobiluncus sp e Peptostreptococcus sp) $(21,24)$.

As vaginites e vaginoses apresentam uma possível correlação com o câncer do colo doútero por facilitarem a infecção da paciente pelo papilomavírus humano (HPV) $(25,26)$, que é uma condição diretamente relacionada ao surgimento dessa neoplasia $(27,28)$. Das mulheres analisadas no presente estudo, menos de $15 \%$ apresentavam a presença de um ou mais agentes patológicos (Tabela 1).

Tabela 1 - Agentes patológicos, presentes nos exames de preventivo registrados na clínica ginecológica de atendimento particular e conveniado de Curitiba-PR no período de dezembro de 2004 a abril de 2009

\begin{tabular}{lc}
\hline Agente Patológico & Número de amostras \\
\hline Candida sp & $114(1,9 \%)$ \\
Trichomonas vaginalis & $21(0,4 \%)$ \\
Gardnerella vaginalis & $453(7,6 \%)$ \\
Herpes vírus & $3(0,05 \%)$ \\
Chlamydia Trachomatis & $7(0,12 \%)$ \\
HPV & $30(0,5 \%)$ \\
Leptothrix sp & $45(0,8 \%)$ \\
\hline
\end{tabular}

Fonte: COMAR, 2009 (27).

Conforme os resultados da pesquisa, a Gardnerella vaginalis, um dos agentes bacterianos mais frequentemente associados à vaginose bacteriana, foi o agente responsável por 7,6\% dos casos caracterizados como inflamação acentuada. Esse agente possui como principais características: a modificação do $\mathrm{pH}$ acima de 4,5 , corrimento abundante brancoacinzentado e de odor fétido (peixe podre), sendo o corrimento e o odor oriundos da produção de aminopeptidases, que, por serem citotóxicas, ocasionam a esfoliação das células epiteliais e o corrimento 
Análise dos resultados de exames preventivos e de rastreamento de câncer de colo do útero realizados em uma clínica ginecológica particular no município de Curitiba, PR

vaginal, ou seja, agridem o epitélio cérvico-vaginal de forma intensa $(21,22)$. A infecção por esse agente bacteriano tem sido comumente associada a fatores socioculturais como: idade; falta de educação sexual adequada; maus hábitos de higiene; grande número de parceiros; início precoce da vida sexual ativa, principalmente associada à falta de uso de preservativos (24).

Em 1,9\% das amostras foi observada a presença de Candida sp. Como esse agente é raramente isolado em mulheres pré-menárquicas ou na pós-menopausa, sugere-se dependência hormonal para a ocorrência da infecção, em razão do aumento da quantidade de glicogênio, principalmente no período pré-menstrual. Além disso, a ocorrência está associada a hábitos sexuais, higiênicos ou comportamentais (24).

O Trichomonas vaginalis é o agente causador da DST não viral mais comum e foi observado em $0,4 \%$ das amostras. A infecção apresenta uma ampla variedade de manifestações clínicas, desde quadro assintomático até severa vaginite. A tricomoníase tem sido associada à transmissão do vírus da imunodeficiência humana (HIV), à doença inflamatória pélvica, ao câncer cervical, à infertilidade, ao parto prematuro e ao baixo peso de bebês nascidos de mães infectadas (29). Na citologia convencional quando há a presença desse micro-organismo, ele apresenta-se com formato de pêra oval ou redondo, cianofílico, e pode variar de tamanho entre $15 \mu \mathrm{m}$ e $30 \mu \mathrm{m}$ (16).

O HPV foi observado em apenas $0,5 \%$ das amostras. É importante ressaltar que o método Papanicolaou detecta somente as alterações induzidas por HPV e não o vírus propriamente dito, o que determina uma baixa sensibilidade. Apenas métodos moleculares são capazes de identificar o vírus, como captura híbrida e reação em cadeia da polimerase (30, 31). O índice de citologia falso negativo tem sido estimado entre $20 \%$ e $40 \%$ (32, 33). Portanto, se fossem realizados métodos moleculares para a detecção do HPV, esse resultado obtido poderia ser superior.

O presente estudo apresentou resultado negativo para lesão intraepitelial e malignidade (NILM) em 5.677 (95,1\%) amostras analisadas e 163 (2,71\%) amostras apresentaram células escamosas atípicas de significado indeterminado (ASCUS). Entre as amostras que apresentavam algum tipo de lesão, 100 amostras $(1,61 \%)$ obtiveram diagnóstico citológico de lesão intraepitelial escamosa de baixo grau (LSIL), 4 amostras $(0,07 \%)$ lesão intraepitelial escamosa de alto grau (HSIL) e 8 amostras $(0,14 \%)$ com presença de células escamosas atípicas, não sendo possível excluir uma HSIL (ASC-H).
Atipias em células glandulares foram verificadas em 19 amostras $(0,35 \%)$ e somente 1 adenocarcinoma $(0,02 \%)$ foi relatado na população de estudo.

\section{Conclusóes}

A investigação laboratorial de lesões do colo uterino, pelo exame de Papanicolaou, é essencial na prevenção desse tipo de câncer e a detecção precoce de lesões permite que seja adotada uma conduta terapêutica adequada que evita a progressão da doença. Contudo, para que esse método possa ser realizado em sua máxima eficácia, é essencial que a coleta seja feita de modo adequado para que a amostra se apresente satisfatória para a análise. E, além da detecção das lesões do colo uterino, o teste de Papanicolaou também é importante na detecção e/ou sugestão da presença de alguns agentes patológicos, o que permite a adoção de um tratamento apropriado e do controle da propagação da infecção.

\section{Referências}

1. Duavy LM. A percepção da mulher sobre o exame preventivo do câncer cérvico-uterino: estudo de caso. Ciênc Saúde Coletiva. 2007;12(3):733-42.

2. Oliveira MM. Câncer cérvico uterino: um olharcrítico sobre a prevenção. Revista Gaúcha Enfermagem. 2004;25(2):176-83.

3. Instituto Nacional do Câncer. Ministério da Saúde. Secretaria Nacional de Assistência à Saúde. Coordenação de Prevenção e Vigilância. Atlas de mortalidade por câncer no Brasil. Rio de Janeiro: INCA; 2009.

4. Nunes J. Confiabilidade e validade das declarações de óbitos por câncer de útero no município de Belém, Pará, Brasil. Cad Saúde Pública. 2004;20(5):1262-8.

5. Amaral RG, Ribeiro AA, Miranda FA, Tavares S, Souza LNA, Manrique EJC, et al. Fatores que podem comprometer a qualidade dos exames citopatológicos no rastreamento do câncer do colo do útero. Rev Bras Anal Clin. 2006;38(1):3-6.

6. Ferreira MLM, Oliveira C. Conhecimento e significado para funcionárias de indústrias têxteis sobre prevenção do câncer do colo-uterino e detecção precoce do câncer da mama. Rev Bras Cancerologia. 2006;52(1):5-15. 
7. Coelho RA, Facundo MKF, Nogueira AL, Sakano CRSB, Ribalta JCL, Baracat EC. Relação entre diagnóstico citopatológico de neoplasia intra-epitelial cervical e índices de células CD4+ e de carga viral em pacientes HIV-Soropositivas. Rev Bras Ginecol Obstet. 2004;26(2):97-102.

8. Lima CA, Palmeira JAV, Cipolotti R. Fatores associados ao câncer do colo uterino em Propriá, Sergipe, Brasil. Cad Saúde Pública. 2006;22(10):2151-6.

9. Souto R, Falhari JPB, Cruz AD. O papilomavírus humano: um fator relacionado com a formação de neoplasias. Rev Bras Cancerol. 2005;51(2):155-60.

10. Widicce LE, Moscicki AB. Updated guidelines for Papanicolaou tests, colposcopy, and human papillomavirus testing in adolescents. J Adolescent Health. 2008;43(4):41-51.

11. CastellsaguéX. Natural history and epidemiology of HPV infection and cervical cancer. Gynecol Oncol. 2008;110(3 Suppl 2):S4-7.

12. Hackenhaar AA. Exame citopatológico de colo uterino em mulheres com idade entre 20 e 59 anos. Rev Bras Epidemiol. 2006;9(1):103-11.

13. Hewitt M, Devesa SS, Breen N. Cervical cancer screening among U.S. women: analyses of the 2000 National Health Interview Survey. Prev Med. 2004;39(2):270-8.

14. Noronha VL, Noronha R, Carmona B, Macedo LA, Cruz EM, Naum C, et al. Papilomavírus humano em mulheres com citologia oncótica dentro dos limites da normalidade. DST - J Bras Doenças Sex Transm. 2005;17(1):49-55.

15. Derchain SFM, Filho AL, Syrjanem KJ. Neoplasia intra-epitelial cervical: diagnóstico e tratamento. Cervical intraepithelial neoplasia: diagnosis and treatment. Rev Bras Ginecol Obstet. 2005;27(7):425-33.

16. Solomon D, Nayar R. Sistema Bethesda para citopatologia cervicovaginal: Definições, critérios e notas explicativas. 2a ed. Rio de Janeiro: Revinter; 2005.

17. World Health Organization - WHO. Information Centre on Human Papilloma Virus (HPV) and Cervical Câncer. [acesso 20 jul. 2008]. Disponível em: http://www.who.int/hpvcentre/statistics/en/.

18. Parkin DM, Whelan SL, Ferlay J, Teppo L, Thomas DB. Cancer incidence in five continents Vol. VIII. Lyon: IARC Scientific Publications; 2002. n. 155.
19. Martin-Hirsch P, Jarvis G, Kitchenet H. Collection devices for obtaining cervical cytology samples. Cochrane Database Syst Rev. 2000;(2):CD001036.

20. Ministério da Saúde. Proposta de laudo e nomenclatura dos exames citopatológicos. Ministério da Saúde e Sociedade Brasileira de Citopatologia. [acesso 20 jul. 2008]. Disponível em: http://www.saude.gov. br. Programas e projetos. Câncer de colo uterino conduta clínica.

21. Wanderley MS. Bacterial Vaginosis. In: Menopausal women and in women with infertility. Rev Bras Ginecol Obstet. 2001;23(10):641-6.

22. Lima TM. Análise dos laudos citopatológicos de um centro de parto natural em Fortaleza-CE: um estudo descritivo. [acesso 30 ago. 2009]. Disponível em: http://www.uff.br/objnursing/index.php/nursing/ article/viewArticle/j.1676-4285.2009.2354/html_25.

23. Araújo S. Citologia e histopatologia básicas do colo uterino para ginecologistas. [acesso 30 ago. 2009]. Disponível em: http://www.aprp.org.br/livro_total.pdf.

24. Ribeiro AA. Agentes microbiológicos em exames citopatólogicos: estudo de prevalência. Rev Bras Anal Clin. 2007;39(3):179-81.

25. Muñoz N. Human papillomavirus and cancer: the epidemiological evidence. J Clin Virol. 2000;19(1-2):1-5.

26. Schiffman M, Kjaer SK. Chapter 2: natural history of anogenital human papillomavirus infection and neoplasia. J Natl Cancer Inst Monogr. 2003;(31):14-9.

27. Muñoz N, Bosch FX, de Sanjosé S, Herrero R, Castellsagué X, Shah KV. Epidemiologic classification of human papillomavirus types associated with cervical cancer. N Engl J Med. 2003;348(6):518-27.

28. Cogliano V, Baan R, Straif K, Grosse Y, Secretan B, El GF, et al. Carcinogenicity of human papillomaviruses. Lancet Oncol. 2005;6(4):204.

29. Maciel GP, Tasca T, De Carli GA. Aspectos clínicos, patogênese e diagnóstico de Trichomonas vaginalis. J Bras Patol Méd Lab. 2004;40(3):152-60.

30. Nobuyoshi KE, Suzuki LE, Taguti Irie MM, Yoshida CS, da Silva FMS, Lopes CME. Importância da aplicação de critérios morfológicos não clássicos para o diagnóstico citopatológico de papilomavírus humano (HPV) previamente detectado por PCR. Acta Bioquím Clín Latinoam. 2005;39(1):61-8. 
Análise dos resultados de exames preventivos e de rastreamento de câncer de colo do útero realizados em uma clínica ginecológica particular no município de Curitiba, PR

31. Lorincz AT, Richart RM. Human Papillomavirus DNA testing as an adjunct to cytology in cervical screening programs. Arch Pathol Lab Med. 2003; 127(8):959-68.

32. Wright Jr TC. Cervical cancer screening in the $21^{\text {st }}$ century: is it time to retire the PAP smear? Clin Obstet Gynecol. 2007;50(2):313-23.
33. Instituto Nacional do Câncer-INCA. Câncer do colo do útero. [acesso 20 jul 2009]. Disponível em: http:// www.inca.gov.br/conteudo_view.asp?id=326.

Recebido: 17/05/2009

Received: 05/17/2009

Aprovado: 24/09/2009

Approved: 09/24/2009 